\title{
EDUCAÇÃO DE JOVENS E ADULTOS E EDUCAÇÁO POPULAR: UM OLHAR HISTÓRICO SOBRE AS POLÍTICAS PÚBLICAS OU AUSÊNCIA DELAS
}

Dulcinéia de Fátima Ferreira Pereira

Embora em nossa Constituição, no artigo 208, conste que o Ensino Fundamental é direito de todos, o que temos visto é que nem sempre o Estado assume suas responsabilidades políticas e econômicas, no que se refere à oferta e qualidade da educaçâo pública e gratuita, principalmente para jovens e adultos. Neste artigo, revisitamos a história buscando analisar as políticas públicas para a Educação de Jovens e Adultos, ou a ausência delas nos últimos 40 anos. Esta reflexão também expressa a estreita relaçáo que há entre a Educaçáo de Jovens e Adultos e a educação popular.

Palavras-chave: Alfabetização de jovens e adultos. Educação de Jovens e Adultos. Educação popular. Políticas públicas
Doutora e mestra em Educação - Unicamp;

Docente - Unianchieta. Jundiaí - SP [Brasil] dulceferreira@terra.com.br 


\section{Introdução}

Para nós, falar sobre a Educação de Jovens e Adultos é, sem dúvida, um exercício intenso, pois implica colocarmos em debate nosso jeito de pensar, sentir e viver. É um exercício que envolve um emaranhado de acontecimentos que não se dão apenas no campo teórico; é, portanto, um exercício que envolve posicionamento político, principalmente por sabermos que a EJA não chegou a ter reconhecido seu devido valor em relação aos poderes públicos. Podemos observar, nos últimos quarenta anos, a ausência de políticas voltadas para a Educação de Jovens e Adultos; no entanto, nem por isso nos colocamos numa posição fatalista. Neste artigo também pretendemos estabelecer um olhar histórico e estreito sobre a Educação de Jovens e Adultos e a Educação Popular, pois entendemos que mesmo a educação "[...] não sendo fazedora de tudo é um fator fundamental na reinvenção do mundo" (FREIRE, 200o, p. 14). Foi vivenciando experiências de Educação Popular que aprendemos isso.

Por se tratar de um olhar histórico, é importante lembrar que, em razão de a História não ter apenas mão única e nem sempre os fatos ocorrerem de forma linear, ela vai sendo construída no entrecruzamento de tantos outros acontecimentos, muitas vezes silenciosos.

\section{Um ponto de partida}

Este olhar histórico se inicia no fim da década de 1940, período em que questóes relacionadas à educação de base começam a aparecer no país, pois o final da II Guerra Mundial trouxe, para o mundo, a vitória dos ideais democráticos. Essa conjuntura internacional interferiu nas mobilizaçóes nacionais da época, que acabaram dando ênfase ao movimento pela educação das massas. À medida que se buscava o progresso social e econômico do país, tornava-se necessário pensar numa política de educaçáo de base. $\mathrm{Na}$ década 
de 1950, iniciam-se as campanhas de alfabetização de adultos, pois, com a modernização da sociedade, era preciso um maior ajustamento da população, principalmente a rural.

Segundo Freire (2006, p. II5), o Governo de Juscelino Kubitscheck "[...] mostrava-se politicamente preocupado com a miséria do nosso povo [...]"; entre as preocupações desse governo estavam as questôes educacionais. Foi nesse contexto que, em 1958, ocorreu o II Congresso Nacional de Educação de Adultos. Nesse evento, os educadores manifestaram diferentes posiçóes sobre uma nova perspectiva educacional, não se preocupando somente com métodos eficazes, mas também com as conseqüências políticas, sociais e econômicas de seus trabalhos. O educador Paulo Freire apresentou, na ocasião, uma proposta de educação que preconizava uma alfabetização para a liberdade.

\section{[...] Afirmava que só se faria um trabalho para a democracia se o processo de alfabetização de adultos não fosse sobre - vertical- mente - ou para - assistencialmente - o homem, mas com o ho- mem, com os educandos, com a realidade (FREIRE, 2006, p. 124, grifos do autor).}

Esse período também foi marcado por mobilizaçôes em favor da educação de adultos, iniciando-se a discussão sobre a questão do preconceito contra $\mathrm{o}$ analfabeto e uma luta para que se mudasse a visão preconceituosa sobre $o$ analfabeto, como um ser incapaz e deficiente.

A liberdade de expressão, característica dos últimos anos do governo Kubitschek, e a efervescência política dos primeiros anos da década de I960, contribuíram para que estudantes, intelectuais, educadores, políticos etc. buscassem a construção de um projeto político que possibilitasse a superação e a dominação do capital sobre o trabalho e tudo que dessa dominação decorresse.

No início dos anos 1960, nasce o Movimento de Cultura Popular de Recife $(\mathrm{MCP})^{\mathrm{r}}$. Esse movimento tinha a intenção de levar a todas as pessoas
I "Os diversos relatos disponíveis sobre a criação do Movimento de Cultura Popular coincidem em afirmar que ele foi instituído sob a inspiração e o patrocínio direto da Prefeitura do Recife. Em maio de I960, o então prefeito Miguel Arraes promoveu, apoiado em setores progressistas da intelectualidade e nos estudantes, a fundação do Movimento de Cultura Popular. Juridicamente nascia o MCP como uma sociedade civil autônoma. Suas atividades iniciais se orientaram, fundamentalmente, no sentido de conscientizar as massas através da alfabetização e educação de base. A realidade de um Estado com enorme índice de analfabetismo exigia esforços urgentes a fim de incorporar à sociedade os milhares de proletários e marginais do Recife, dotandoos de uma nova consciência. Com o tempo, o MCP foi diversificando seu campo de ação, e novos tipos de contato com a massa se foram forjando: teatro, núcleos de cultura popular, meios informais de educação, canto, música e dança popular, artes plásticas e artesanato.” (BEISEGEL, I989, p. I I9). 
2 "Não era só levar para a gente dos bairros pobres aquilo que se podia assistir no dos ricos. $O$ pessoal do MCP sabia que todas as pessoas, todas as famílias, todas as comunidades e todo o mundo tinham a sua própria cultura. Você vai num 'fundo do mundo', vai lá num 'oco do sertáo' e lá vive uma gente. E vive como gente, as pessoas falam umas com as outras e se entendem. Elas criam famílias. Elas plantam na terra e colhem. Fazem a comida e sabem oraçóes que se rezam antes de comer. Pintam potes de barro, criam cançôes bonitas e fazem lindas colchas de fiandeira. As pessoas 'de lá' têm seus conhecimentos sobre as plantas e os bichos e sabem tratar muita doenças. Elas têm os seus muitos cantos e as suas alegres danças. Elas criam e possuem as suas crenças e os seus saberes. Isso mesmo. Povo nenhum, dos índios da Amazônia a Sáo Paulo ou Rio de Janeiro, vive sem conviver com tudo Isso. E é assim que se fala que cada gente, cada povo do Brasil e do Mundo possui uma cultura própria." (BRANDÃO, 200I, p. 37). a cultura produzida pelo povo. O MCP pretendia trabalhar com educaçáo e cultura popular, mais do que levar a cultura ${ }^{2}$, pretendia resgatar, nas pessoas, o seu potencial criador. Reafirmava, na prática, que todo ser humano produz cultura na sua relação com o outro e com o mundo.

É nesse contexto que a proposta de educação de Paulo Freire, que consiste no processo de alfabetização pautado nos princípios da Educaçáo Popular, expande-se, passando a ser um espaço, em que o educando encontra possibilidades de reinventar-se na história, ultrapassando sua situação de homem objeto para homem sujeito-histórico transformador.

Paulo Freire dizia que educação não poderia ser vista apenas como ferramenta para a transmissão de conhecimentos e reprodução das relaçôes de poder, mas sim como um ato político de libertação e emancipação das pessoas. Enxergava na relação pedagógica uma ação política. Pois compreender o saber como mera transmissão ou como criação e recriação humana; tratar o educando como sujeito ou como objeto do processo, faz uma grande diferença na vida das pessoas. (PEREIRA, 2006, p. 52).

Em meio a essa mobilização política com participação popular, a conjuntura do país começava a mostrar sinais de mudança, pois os militares vinham-se articulando politicamente, com raízes profundas vinculadas aos interesses econômicos sólidos internos e externos, com respaldos sociais expressivos e comprometidos com o capital estrangeiro.

\section{Anos de ebulição e repressão}

Em 3 I de março de I964, as forças da direita instalam-se no país por meio do golpe militar, com a intenção de barrar o avanço das mobilizaçóes 
populares. Nesse contexto, a intensa mobilização dos programas de educação de adultos passa pelo controle da nova ordem vigente, pois "[...] os programas promovidos a partir do início dos anos 60 apareciam como um perigo para a estabilidade do regime, para a preservaçáo da ordem capitalista." (PAIVA, 1987, p. 259).

As idéias políticas discutidas nos grupos de alfabetização de adultos poderiam dificultar o processo de dominação pretendido; por esse motivo, logo após o golpe militar, inicia-se o desaparecimento dos grupos de educação de adultos com práticas conscientizadoras.

Segundo Vale (1992), diante da repressáo violenta nascida a partir de I964, esse movimento educacional, de cunho extremamente político e conscientizador, foi duramente atingido. Entre os grandes movimentos de alfabetização da época, o único que se manteve em exercício foi o Movimento de Educação de Base $(\mathrm{MEB})^{3}$, devido a seu vínculo com a Conferência Nacional dos Bispos do Brasil (CNBB), embora sua sobrevivência tenha custado a revisão de sua metodologia, de seu material didático e a orientação do seu programa.

As experiências com educação popular sofrem sérias conseqüências, pois nessa época foi proibido pensar, falar, criticar, e aquele que ousasse desafiar a ordem ou expressar algum grau de envolvimento com as causas populares era duramente reprimido, torturado, exilado e até mesmo silenciado para sempre, de forma brutal. Justamente pelas idéias que cultivava a respeito de uma educação que poderia contribuir para mudar o mundo ${ }^{4}$, Freire começou a incomodar, pois suas idéias se estavam espalhando muito rapidamente pelo Brasil. Assim, foi taxado de comunista, subversivo e, em seguida, exilado com tantos outros brasileiros.

Esse foi um período em que a sociedade civil viveu um conflito bastante acirrado, momento em que as classes sociais lutaram para defender seus interesses. Logicamente, a força militar foi utilizada para defender os interesses daqueles que dominavam economicamente o país, fazendo calar, por longo
3 "O MEB (Movimento de Educação de Base) criado desde 6I e funcionando com recursos da Uniâo, a partir de 62 , começa a caracterizar-se como um movimento de cultura popular "este deveria fundamentalmente oferecer uma educação de base que levasse ao camponês uma concepção de vida, tornando-o consciente de seus valores físicos espirituais, morais e cívico; um estilo de vida, que guiasse seu comportamento nas esferas pessoal, familiar e social; e uma mística de vida que atuasse como uma força interior que assegurasse dinamismo e entusiasmo no cumprimento dos seus deveres e no exercício de seus direitos." (PAIVA, I987, p. 24I).

4 "Paulo Freire e muitos outros educadores brasileiros sabiam que a Educação não muda o mundo. Mas a educação ajuda a mudar as pessoas. E ela muda as pessoas ensinando elas a saber ler melhor, a saber pensar melhor, a saber julgar melhor o que está acontecendo, a saber agir melhor, juntas, uma ao lado das outras. E assim, as pessoas que sabem ler palavras lendo o mundo, haveriam de saber mudar o mundo. Saberiam como fazer um mundo melhor para a vida de pessoas mais felizes." (BRANDÃO, 200I, p. 42). 
período, as lutas populares em defesa da democracia, da liberdade, e, entre outras, pelo direito à educação. "Os movimentos de educação popular foram destruídos e seus educadores e aliados cassados, presos e exilados. Para eles, como para as lideranças dos trabalhadores, começa o caminho em direçáo aos 'anos de chumbo'[...]'(GÓES, I994, p. 34). Sob o impacto repressivo da ditadura militar os movimentos sociais foram contidos à força.

Com o poder instalado, os dois primeiros anos de ditadura foram anos em que náo se falou nem se investiu em educaçáo de adultos. Na verdade, o que se pretendia com esse silêncio era fazer uma intervenção na educação que apagasse a prática dos anos anteriores ao golpe e disseminasse a idéia de neutralidade política na educação.

Novos mecanismos foram desencadeados: a repressão se abateu sobre os intelectuais comprometidos com as reformas, e o Estado foi buscar meios de criar novos quadros. Não precisou procurar muito. À mão estava a sua fonte de poder: a Aliança para o Progresso. A USAID, agência confiável, desincumbiu-se da missão (GÓES, I994, p. 32).

Confiando à United States Agency for International Development (USAID) todo sistema educacional, o governo atribui a essa agência a missão de reordenar a educação nacional de forma sigilosa. Os acordos MECUSAID

[...] cobriram todo o espectro da educação nacional, isto é, o ensino primário, médio e superior, a articulação entre os diversos níveis, o treinamento de professores e a produçáo e veiculação dos livros didáticos. A proposta da USAID não deixava brecha [...] (GÓES, I994, p. 33). 
Esses acordos enfraqueceram os movimentos de educaçáo e cultura popular, atendendo, assim, aos objetivos do regime militar, que era desarticular os trabalhos voltados à conscientizaçáo.

Encarando o analfabetismo como um fardo para o indivíduo e para a sociedade e sua erradicaçáo como uma exigência cívica, podemos ver, de volta, o entusiasmo pela educação, que reaparece tentando "salvar" o analfabeto da situação marginal em que se encontrava, ao mesmo tempo que busca a sedimentaçáo do poder político, das estruturas da sociedade e da segurança interna do regime.

Em 1966, o governo também entrega à orientação norte-americana a educação dos adultos. Com a assessoria da USAID, retoma o problema da educação de adultos, adotando preferencialmente o nordeste para desenvolver as atividades, pois esse era o local "[...] onde os programas anteriores haviam semeado idéias, que precisavam ser neutralizadas [...]" (PAIVA, 1987, p. 26I).

A primeira manifestação do governo em relação à educação de adultos é de 28 de fevereiro de 1966 (decreto $\mathrm{n}^{\circ}$. 57.895), quando o Presidente da República determinou que os saldos não aplicados nos Fundos Nacionais do Ensino Primário e Médio deveriam ser aplicados pelo MEC a fim de atender, entre outros objetivos, o ensino fundamental das pessoas analfabetas de mais de ro anos. As parcelas não utilizadas do FNEP e demais recursos orçamentários que, de futuro, fossem consignados para esse fim, seriam aplicados em programas intensivos de erradicação do analfabetismo que deveriam durar até que as taxas dos que não soubessem ler e escrever se reduzissem a menos de $15 \%$ da populaçấo de Io anos e mais. (PAIVA, 1987, p. 264).

Como em 1967, a proposta de aplicação desses recursos ainda não havia sido implementada; cria-se o Movimento Brasileiro de Alfabetização 
(MOBRAL) com objetivos políticos claramente definidos. É importante lembrar que todos os programas de educação de adultos, até então elaborados pelos governos anteriores, sempre tiveram objetivos políticos por trás, mas com o MOBRAL “[...] é a primeira vez que a alfabetização assume caráter tão evidentemente ideológico e visa de forma tão explícita inculcar no operariado os valores do capitalismo autoritário.” (FREITAG, I986, p. 92).

A concepção de alfabetização do MOBRAL era completamente diferente daquela defendida por Paulo Freire. No entanto, Freitag (1986) afirma que eles não hesitaram em utilizar as técnicas de alfabetização de Freire, extraindo-as de seu contexto filosófico e político. Pode-se dizer que o que ficou conhecido como método Paulo Freire foi refuncionalizado como prática, não de liberdade, mas de integração ao "modelo brasileiro" no nível das três instâncias: infra-estrutura, sociedade política e civil.

$\mathrm{Na}$ implantação do MOBRAL pelo governo militar, até se admitia que haveria necessidade de desenvolver um trabalho conscientizador, porém com um enfoque diferente daquele realizado antes de 1964, pois esse Movimento fazia claras restrições à concepção político-filosófica de Paulo Freire. Nesse sentido, falavam de "conscientização" cívica em busca da ordem e do progresso.

O MOBRAL estimulava o individualismo e a adaptação à vida moderna, enfatizando a responsabilidade pessoal pelo êxito ou fracasso, afastando a possibilidade de uma análise crítica sobre a sociedade que pudesse abalar a ordem vigente.

Mesmo com toda a repressão, a resistência se fez em diferentes instâncias da sociedade civil, refugiando-se em organizaçôes não-governamentais (ONGs), em trabalhos desenvolvidos pela Igreja Católica, sindicatos ou mesmo partidos políticos clandestinos. Muitos buscaram criar formas de manter a mobilização popular. 
As lutas estudantis aumentaram muito nesta época, protestando em manifestaçóes e passeatas de rua contra a falta de verbas, contra o acordo MEC-USAID, contra o ensino pago, contra a falta de liberdade política e a penetração do imperialismo norte-americano no Brasil. (FASE, s/d).

Segundo Cunha (1994), a repressão, o silêncio, o medo, o desespero e a apatia levaram alguns educadores a abandonar o magistério e o estudo. Enquanto alguns se envolviam com a luta armada, a apatia de outros resultou em desleixo no ensino:.

Entre o desespero e a apatia, caminhavam com dificuldade educadores e estudantes que tentavam resguardar a dignidade de sua situação, só possível num ambiente de liberdades democráticas. A história mostrou que esses resistentes tinham razão e, progressivamente, os desesperados e apáticos voltam a reunir-se a eles, nas lutas pela democratização do ensino em nosso país (CUNHA, I994, p. 4I).

Durante o governo Geisel (74-78), já se ouvia falar em "abertura política”; no entanto, o regime continuou a empregar as leis de exceçãos, "[...] perseguição às lideranças populares e democráticas, torturas e assassinatos políticos, com a desculpa de proteger a ordem pública, as instituiçôes democráticas, a Segurança Nacional e o desenvolvimento do país." (CEPIS, I980, p. 38).

No fim dos anos 1970 e início dos I980, mais uma vez o povo volta às ruas. Aumentam os movimentos contra o custo de vida, pela anistia, pela democracia e abertura política. Os movimentos populares ganham corpo e, em decorrência, greves e manifestaçóes políticas se espalham pelo país. A garra e a esperança que moveram as pessoas envolvidas nessas lutas trouxeram de volta para o país a possibilidade de reconstruir uma nação democrática, mais justa e mais humana.
5 "Leis de exceção são aquelas que permitem o uso da força da repressão e da censura, numa situação considerada pelo governo como especial." (CEPIS, I980, p. 66). 


\section{$4 \quad$ É tempo de se levantar}

Mais uma vez, aqueles que sonhavam com um mundo mais justo se levantaram, organizaram-se em sindicatos, organizaçoes populares, associaçôes de bairros e conseguiram trazer à tona as discussóes sobre a necessidade de democratização do país. É nesse contexto que as lutas populares conquistam a anistia para os presos políticos, e o país começa a mudar sua "cara".

Segundo Saviani (1995), podemos afirmar que, do ponto de vista da organização do campo educacional, a década de 1980 é uma das mais fecundas de nossa história. A mobilização desses anos orientou-se pela bandeira de transformar a educação e a escola em instrumento de reapropriação do saber por parte dos trabalhadores, saber esse que viria, mais tarde, a contribuir para uma maior participaçáo na sociedade:

É a década, sem dúvida, de maior participação cidadã no país. Os "novos personagens" rompem a cena e exigem direitos, inclusão no contrato social, alargamento dos direitos de cidadania, sejam políticos, sociais, econômicos ou culturais. O movimento sindical combativo que cria, em 83, a Central Única dos Trabalhadores (CUT), os movimentos populares que fundam a Central dos Movimentos Populares, os trabalhadores Rurais Sem Terra, que constituem o MST em 1985, e o movimento político que cria ou reconstrói, partidos de esquerda, particularmente o PT. [...] Em I984, o país assiste ao chamado "Movimento das Diretas Já", que leva às ruas e praças milhôes de pessoas reivindicando o direito básico de poder votar para Presidente da República. Esse grande movimento emancipatório (BSS, 200ob, 200I) obtém a redemocratização do país e consolida seus direitos de cidadania na constituição de I988 [...] (PEREIRA, 2003, p. 4). 
Foi durante essa década, em 1985, que o governo da “[...] Nova República, sem consultar seus 300 mil educadores, extingue o MOBRAL e cria a Fundação Educar, com objetivos mais democráticos, mas sem os recursos de que o MOBRAL dispunha” (GADOTTI, 200o, p. 36). Tivemos também a promulgação da Constituição Nacional, em I988, que trouxe, no seu interior, algumas conquistas para a classe trabalhadora, entre as quais podemos apontar o direito de o analfabeto votar e a obrigatoriedade em conjunto com a gratuidade do ensino fundamental, independentemente da idade de quem o procure.

Sem dúvida, a nova Constituição se apresentou como um grande desafio para a sociedade e o Estado, pois os problemas do sistema educacional brasileiro refletiam uma prática política e econômica, que se contradiziam a nova Lei.

Em I989, o Brasil vive um momento político profundamente significativo: as eleições municipais e federais. Segundo Damaceno (I990), o presidente eleito, Fernando Collor de Mello, assume a política neoliberal e apresenta um plano para a educação que incentiva o setor privado e, ao mesmo tempo, desobriga o Estado de suas responsabilidades sociais. No campo da alfabetização, cria o Plano Nacional de Alfabetização e Cidadania (PNAC) “[...] apresentado com grande pompa publicitária em I990 e extinto no ano seguinte sem qualquer explicação para a sociedade civil.” (GADOTTI, 2000, p. 36). Dessa forma, esse governo desrespeita a Constituição e acaba reproduzindo as condiçóes sociais e políticas geradoras de analfabetismo.

No campo municipal, podemos ver a vitória do Partido dos Trabalhadores (PT) na cidade de São Paulo, elegendo, como prefeita, Luíza Erundina, que convida o professor Paulo Freire para assumir a Secretaria Municipal de Educação da Cidade ${ }^{6}$. Freire aceita o convite e, como secretário, cria o Movimento de Alfabetização de Adultos (MOVA), retomando e atualizando princípios de educação e cultura popular desenvolvidos na década de I960:
6 Sobre esta experiência ver FREIRE, P. Educação na cidade, I99I. 
[...] na realidade, o Mova inaugurou um novo tipo de educação popular, de educação de adultos, no qual dialeticamente se envolvem alfabetizandos/comunidade/poder estatal organizado. O Mova-SP tornou-se modelo de educação popular e de alfabetização de adultos para muitas das secretarias municipais de educação de governos progressistas e outras instituiçôes educativas [...] (FREIRE, 2005, p. 23).

Desde o fim dos anos I980, com a instalação do neoliberalismo no Brasil, a globalização da exclusão vem-se constituindo como política pública, que tem o discurso da inclusão, mas a prática da exclusão; o discurso da qualidade e a prática do sucateamento dos serviços públicos; o discurso da autonomia e a prática do controle. "Nos idos de 1992, alguns resultados do processo de destruição iniciado pelo governo Collor já eram visíveis: desorganização da economia, desemprego e desmonte do aparato estatal, sobretudo na área social." (SOARES, 2002, p. 7).

Podemos afirmar que durante o Governo Collor não houve investimento em políticas para a educação de adultos. Paralelamente ao descaso do Governo Federal, no entanto, muitos grupos de alfabetização de adultos ressurgem por meio de comunidades, sindicatos e ONGs. A experiência do MOVA também se espalha por todo o Brasil, sendo implementada por Estados e Municípios com governos democráticos.

Em 1990, Ano Internacional da Alfabetização, ocorre em Jomtiem (Tailândia) a Conferência Mundial sobre Educação para Todos (convocada pela Organização das Nações Unidas para a Educação, a Ciência e a Cultura [Unesco]). Nela, os países envolvidos discutem e elaboram um documento que ficou conhecido como "A Declaração Mundial Sobre Educação Para Todos". Uma das questóes abordadas nesse documento é a necessidade de maior cooperação entre as nações, no que se refere à garantia da satisfação das necessidades básicas para a aprendizagem. 
Após participação nessa conferência internacional, o Brasil inicia a elaboração do Plano Decenal de Educação para Todos e, nesse plano, afirma que o governo brasileiro estaria pondo em prática os compromissos assumidos em Jomtien:

Os compromissos que o governo brasileiro ora assume, de garantir a satisfação das necessidades básicas de educação de seu povo, expressam-se no Plano Decenal de Educação para Todos, cujo objetivo mais amplo é assegurar, até o ano 2000, às crianças, jovens e adultos, conteúdos mínimos de aprendizagem que atendam necessidades da vida contemporânea. (BRASIL, I993, p. I2).

O Plano Decenal, aprovado em I993, trouxe uma análise da situação da educação no Brasil e traçou objetivos e metas para a erradicação do analfabetismo em dez anos. O Plano também reconhecia que, para um país se desenvolver, era preciso vencer alguns obstáculos consideráveis, tais como

[...] a heterogeneidade e a rigidez das estruturas econômicas; a concentração do progresso técnico e da riqueza acumulada; os elevados índices de desigualdade regional e social de renda; um mercado interno relativamente limitado em face do seu porte demográfico. (MEC, I993, p. I8).

Apresentando dados alarmantes sobre o número de crianças que ainda permanecem sem escola, o Plano apontava, como reflexo dessa situação, o crescimento do analfabetismo; por este motivo, além de firmar compromissos com a universalização do ensino fundamental, propunha a erradicação do analfabetismo em dez anos., Para isso, seria necessária a sistematização da Educação de Jovens e Adultos por meio da educaçáo continuada: 
Faz-se necessário estruturar e institucionalizar programas alternativos de educação continuada com o objetivo de reduzir o contingente atual de analfabetos entre I5-29 anos e elevar os níveis médios de escolaridade dos jovens adultos subescolarizados. Entretanto eles devem resultar de novos acordos de articulação entre as administraçôes estaduais, municipais de ensino, instituiçôes especializadas de formação de profissionais e organizações não-governamentais aptas a operá-los em sistema descentralizados, com elevada flexibilidade e versatilidade. Nesses acordos, é necessária a participação de associaçóes representativas da clientela a serem atingidas, sobretudo as de trabalhadores e as patronais. (MEC, I993, p. 4I).

$\mathrm{Na}$ verdade, esse documento vem com propostas e princípios até democráticos. Caso fossem postos em prática, poderiam trazer mudanças para o país, mas, infelizmente, podemos constatar que ele, como tantos outros elaborados, não se cumpriu.

Outro acontecimento que marcou o início desta década foi a extinção da Fundação Educar que havia sido criada para substituir o MOBRAL, deixando o país sem uma proposta política clara para a EJA. Não sendo prioridade para o governo, a

[...] responsabilidade pela política federal de Educação de Jovens e Adultos ficou a cargo da Coordenação de Educação de Jovens e Adultos (Coeja), organismo de quarto escalâo subordinado à Secretaria de Educaçáo Fundamental do Ministério da Educação. (PIERRO, 2003, p. I2).

Novas eleiçôes federais se realizaram no país em I994, sendo eleito para presidente Fernando Henrique Cardoso. A política neoliberal do governo FHC vai permanecer no país até 2002, pois, em 1998, vence as eleiçóes pre- 
sidenciais para o segundo mandato. Entre as açóes realizadas nesse governo, podemos afirmar que a Educação de Jovens e Adultos não foi incluída no campo das prioridades governamentais, tanto que as açóes que ganharam destaque não são desenvolvidas pelo Ministério da Educação. De forma compensatória, alguns programas aparecem em outros Ministérios,

[...] desempenhando um papel que antes era exclusivo do Ministério da Educação, outras instâncias do governo federal começaram a desenvolver programas de alfabetizaçáo de jovens e adultos- por vezes em conjunto com iniciativas de capacitação profissional. Entre as iniciativas mais importantes implementadas no governo Fernando Henrique Cardoso, estiveram, o Planfor, do Ministério do Trabalho; Pronera, desenvolvido pelo Instituto Nacional de Colonização e Reforma Agrária (Incra); o Alfabetização Solidária, e o Recomeço.( PIERRO, 2003, p. 19).

Após um grande debate nacional, em 1996, é aprovada a nova Lei de Diretrizes e Bases da Educação Nacional. A LDB (9394/96)

[...] finalmente sancionada pelo Presidente da República, em 20 de dezembro de 1996, é a síntese contraditória de diferentes projetos políticos e pedagógicos que, por oito anos, se confrontaram em diversas instâncias da sociedade civil, particularmente no Congresso. É contraditória porque incorpora reivindicaçôes do movimento democrático-popular, organizado no Fórum Nacional em Defesa da Escola Pública, e as articula a exigências econômicas, políticas e ideológicas das forças sociais [que estavam] no governo traçando as principais diretrizes para a educação brasileira. (ARMANELLI, s/d, p. 8). 
A nova lei trata da Educação de Jovens e Adultos na SEÇÃO V com apenas dois artigos (art. 37 e 38). A legislação sobre EJA fica superficial, não apresentando propostas concretas que garantam as necessidades básicas para acesso, permanência e aprendizagem do jovem e adulto que náo tiveram oportunidade de estudar. Essa postura contribui para que a Educação de Jovens e Adultos continue sendo classificada como de segunda classe.

Uma das preocupações da LDB está na reorganização do fluxo escolar. Com a intenção de acelerar o fluxo, o governo diminui a idade mínima para exames supletivos de I8 para I4 anos e toma outras medidas, sempre com o intuito de aumentar o número de concluintes do Ensino Fundamental. Nesse caso, a Educação de Jovens e Adultos permanece no campo de programa compensatório, contradizendo os documentos internacionais que apontam para a necessidade da garantia do direito universal à alfabetização e à educação básica.

Segundo Valente (200I), podemos observar que, ao contrário do que propunha a Declaração Mundial de Educação Para Todos, o Plano Decenal e a nova LDB ofereceram "[...] bases para que o governo iniciasse o processo de desmonte da rede federal e por extensáo da rede pública em geral [...] além de dar suporte à centralização tecnocrática e à privatização desenfreada."

Em 1997, ocorre, em Hamburgo, a V Conferência Internacional sobre a Educação de Adultos (CONFINTEA), que também trouxe grande contribuição para os rumos da EJA, no Brasil, pois nela os países participantes, entre os quais o Brasil, reafirmaram a necessidade de promover a Educação de Jovens e Adultos como um meio de configurar um mundo mais justo e mais pacífico. Defenderam o princípio de que a educaçáo se desenvolve ao longo da vida e não apenas em atividades escolarizadas, superando a visão do senso comum de que educação de adultos é somente alfabetizaçáo. Trataram a EJA numa perspectiva de Educação Permanente, ou seja, a educação de adultos pode até se iniciar com a alfabetização, mas não para por aí. 
O documento final dessa Conferência reafirma o papel do Estado, chamando-o para suas responsabilidades políticas e econômicas, e reconhece a necessidade de investir nesse segmento, principalmente em relação às novas exigências sociais, deixando claro que, embora defenda as parcerias com a sociedade civil, o Estado desempenha um papel central na gestão de políticas públicas para EJA, pois ele é, ao mesmo tempo, provedor, consultor e agente financiador.

Algumas das questôes apontadas no documento final da V Confintea estâo presentes no Plano Nacional de Educação (PNE), aprovado em 2000. No entanto, esse novo Plano também vem mascarado de um discurso pseudoprogressista. Alguns exemplos podem ser citados: o PNE aponta a necessidade da participaçáo da comunidade no gerenciamento do processo, reafirma que a educação acontece ao longo da vida, defende a necessidade de facilitar o acesso e desenvolver mecanismos que contribuam para a permanência do educando na escola, reconhece a necessidade do desenvolvimento de técnicas pedagógicas e produção de material didático adequado à EJA. Além disso, aborda o papel social da EJA, principalmente no que se refere à formação profissionalizante, ressalta a necessidade da formação específica do educador e propôe a cooperaçáo interministerial, interinstitucional e intergovernamental.

No PNE, a EJA aparece como uma modalidade de ensino, náo fazendo parte de nenhum nível de ensino. Assim o governo, de certa forma, desresponsabiliza-se de implementar ações mais concretas para essa modalidade.

O Plano assume que "[...] para se acelerar a redução do analfabetismo é necessário agir ativamente tanto sobre o estoque existente quanto sobre as futuras geraçôes" (BRASÍLIA, 2000, p. 79). No entanto, as açóes de investimento do Fundef ficam apenas no campo do ensino fundamental da primeira à oitava série, não se considerando os educandos da EJA para fins de repasse de recursos aos Estados e Municípios que desenvolvem algum trabalho educacional. Em razão disso, fica à margem das discussôes e do financiamento federal. 
FHC vetou, quando da sanção da Lei 9.424/96, precisamente o dispositivo que incluía o desenvolvimento e a manutenção da Educação de Jovens e Adultos no universo dos dispêndios a serem cobertos pelo Fundef [...] seria necessário que o PNE apontasse de modo consistente para superação do estrangulamento da questão do financiamento dessa modalidade de ensino.

Ora, no máximo, o que o PNE se permite como se pode verificar na seção de financiamento - é estabelecer (meta no Io) o uso prioritário de $15 \%$ dos recursos municipais e estaduais destinados ao ensino fundamental cujas fontes não integram o Fundef, Evidentemente tal solução não ultrapassa o umbral de paliativos. (VALENTE, 200I, p. 30).

Chegamos ao século XXI e, por falta de políticas públicas para a Educação de Jovens e Adultos nos últimos 50 anos, o nosso país não conseguiu garantir o direito à alfabetização. Em 2002, Luís Inácio Lula da Silva é eleito presidente e, em 2006, reeleito para o segundo mandato.

Empossado em I $^{\mathrm{o}}$ de janeiro de 2003 , o governo Lula assume o compromisso de desenvolver políticas que pudessem acabar com a fome e o analfabetismo, o que gerou uma grande expectativa na sociedade brasileira. Afirmando que o Brasil não mais podia esperar para virar a página da história de milhóes de pessoas que ainda náo haviam adquirido o direito de ler e escrever, o Governo Federal adota algumas prioridades, que pudessem dar resposta à situação de exclusão em que se encontravam milhóes de brasileiras e brasileiros. Assim, atribuiu ao Ministério da Educação a responsabilidade sobre o problema do analfabetismo no país. Cria a Secretaria Extraordinária de Erradicação do Analfabetismo, que assume a coordenação do programa "Brasil Alfabetizado". Mais tarde, essa Secretaria integrou-se à Secretaria de Educação Continuada, Alfabetização e Diversidade (SECAD). 
Com a intenção de chegar mais perto possível das pessoas que não sabiam ler e escrever, o governo estabeleceu parceria com os diversos segmentos da sociedade que vinham desenvolvendo experiências de alfabetização no país, tais como organizaçóes não-governamentais, sindicatos, comunidades, sociedades amigos de bairros, estados e municípios.

O governo definiu o Brasil Alfabetizado como uma campanha plural, [acolhendo] todas as iniciativas em andamento e uma diversidade de metodologias de alfabetização. Representantes de várias instituiçóes e segmentos sociais foram nomeados para o Conselho Nacional de Alfabetização, [responsável por orientar] os rumos futuros do Programa. (PIERRO, 2003, p. 28).

Muitos Estados e municípios aderiram ao Programa Brasil Alfabetizado, porém a EJA ainda não era considerada como parte da Rede Municipal de Ensino, para efeito de repasse de verbas do Fundef. Durante o primeiro governo Lula, um grande debate se travou na sociedade sobre a ampliação dos recursos destinados ao Fundo de Manutençáo e Desenvolvimento do Ensino Fundamental e ao Fundo de Manutenção e Desenvolvimento da Educação Básica. Nesse caso, a Educação Infantil e a Educação de Jovens e Adultos, que estavam de fora do Fundef, passariam a ser consideradas como parte da Rede municipal e poderiam receber recursos da União por meio do Fundo de Manutenção e Desenvolvimento da Educação Básica e de Valorização dos Profissionais da Educação (Fundeb) para o seu desenvolvimento. No entanto, somente em 2007, no segundo mandato do governo Lula, é que esse Fundo foi aprovado.

Recentemente, em março deste ano, o Ministro da Educação anunciou um Plano de Desenvolvimento da Educação. Nele, podemos ver uma grande preocupação com a não-produção do analfabetismo escolar, ou seja priorizou-se uma atenção mais específica para as séries iniciais e o processo de alfabetização das crianças. Fala-se em metas de aprendizagem, piso salarial nacional, apoio 
aos municípios com índices de desenvolvimento da Educação Básica inferior à média nacional, vinculação da formação continuada dos professores com as universidades e outras medidas. Quanto ao Programa Brasil Alfabetizado, ele continua em vigor, porém, neste segundo mandato, o Ministério está incentivando professores alfabetizadores das redes municipais a assumirem essa tarefa.

Podemos dizer que, depois de tantos anos de exclusão, a Educação de Jovens e Adultos ganha espaço no cenário educacional, sendo incluída como uma das preocupaçóes nacionais. No entanto, ainda temos muito que caminhar para tornar realidade o direito à educaçáo, presente na nossa Constituição, no artigo 208.

\section{Consideraçóes finais}

Estamos aqui, no ano de 2007 , não mais no início, porém não chegamos ao final da história, aliás, a história não tem fim...

Estamos aqui, no tempo que nos cabe viver. Tempo de novos desafios, de incertezas, de sonhos e esperanças, tempo de repensar a realidade que estamos vivendo, de recriar o jeito de ser e estar no mundo...

Entendemos que temos pela frente desafios, tais como estimular os que cruzaram o cerco do analfabetismo e vieram buscar essa nova forma de ver o mundo, por meio das letras, a prosseguir na busca das palavras escritas, e convidar as pessoas que estáo fora do processo de alfabetização, e que pensam não poder mais aprender, a se lançarem neste desafio de desvendar o que está por trás das letras.

Temos também como desafio algo que só cabe ao educador ou educadora: criar uma prática pedagógica dialógica e criativa na EJA, de modo que possamos, por meio do processo de alfabetização, redescobrir como seres criativos dotados de potencial transformador. Assim, continuaremos na caminhada em busca de direitos legalmente instituídos, mas socialmente negados. 


\section{YOUNG AND ADULT'S EDUCATION AND PUBLIC EDUCATION: A HISTORICAL LOOK ABOUT PUBLIC POLICY OR ITS ABSANCE}

Although in our Constitution lay stress on the article 208 that the grade school period is the right of every body, we have noticed that the government doesn't assumed its political and economics responsibilities when the offer and the quality of public education is involved, mainly for young and adults. In this article we took into consideration the history, trying to analyze the public policy for young and adult's education, or the lack of them in the last forty years. This reflection also expresses the close relation between the young and adult's education and the popular education.

Key words: Popular education. Public policy. Young and adults education. Young and adult's teaching.

\section{Referências}

ARMANELLI, J. A. et al. LDB 9.394/96. Belo Horizonte, MG: APUBH, s/d.

CEPIS (Centro de Educação Popular - Instituto Sedes Sapientiae). Como entender melhor a história recente do Brasil. São Paulo, v. I, nov. 1980.

CUNHA, L. A; GÓES, M. O golpe na educação. 8. ed. Rio de Janeiro: Jorge Zahar Editor, 1994.

BEISEGEL, C. R. Política e educação popular: A teoria e a prática de Paulo Freire no Brasil. São Paulo: Ática, I989.

BRANDÃO, C. R. História do menino que lia o mundo. 3. ed. Veranópolis, RS: ITERRA, $200 \mathrm{I}$.

BRASIL. Plano Decenal de Educação para todos. Brasília, DF: MEC, 1993.

BRASIL. Plano Nacional de Educação. Brasília, DF: Câmara dos Deputados, 2000.

CONFINTEA. Declaração de Hamburgo. Brasília, DF: SESI/Unesco, 1997.

DAMASCENO, A; ROCHA, S. A educação "collorida”. Revista Tempo e Presença. São Paulo, CEDI, n. 25I, maio/jun. I990.

FREIRE, A. M. A. Paulo Freire: uma história de vida. Indaiatuba, São Paulo: Villa das Letras, 2006. 
FREIRE, A. M. A. Utopia peregrina. Paulo Freire: a utopia do saber. Revista Memória da Pedagogia, Segmento-Dueto, São Paulo, n. 4, p. 16-29, 2005.

FREIRE, P. Política e educação. 4. ed. São Paulo: Cortez, 20ooa.

FREIRE, P. Pedagogia da indignação: Cartas pedagógicas e outros escritos. São Paulo: Unesp, 20oob.

FREITAG, Bárbara. Escola, Estado e sociedade. 6. ed. São Paulo: Moraes, 1986.

GADOTTI, M; ROMÁO, J. E. (Org.). Educação de Jovens e Adultos: teoria, prática e proposta. 2. ed. São Paulo: Cortez/IPF, 2000.

GUIMARÁES, P. V. A educação na Constituição de 1988. Revista de Educação AEC. Brasília, DF: AEC, ano I7, n. 70, out./dez. 1988.

PAIVA, V. Educação popular e educação de adultos. São Paulo: Loyola, I987.

PEREIRA, D. F. F. Revisitar Paulo Freire: uma possibilidade de reencantar a educação. Tese (Doutorado em Educação)-Faculdade de Educação, Universidade Estadual de Campinas, Campinas, 2006.

PEREIRA, E. T. Cidadania, educação e inclusão: o caso brasileiro. Anais do VI Congresso da Sociedade Portuguesa de Ciências da Educação. "O Estado da Arte" Universidade de Évora - 5 a 7 de julho de 2003.

PIERRO, M. C. Seis anos de Educação de Jovens e Adultos no Brasil. São Paulo: Ação Educativa, 2003.

SAVIANI, D. Os ganhos da década perdida. Revista Presença Pedagógica. v. I, n. 9, nov./dez. 1995 .

SOARES, L. T. Os custos sociais do ajuste neoliberal na América Latina. 2. ed. São Paulo: Cortez, 2002.

VALE, A. M. Educação popular na escola pública. São Paulo: Cortez, I992.

VALENTE, I. FHC sabota o plano. Brasília, DF: Câmara dos Deputados, 20or.

Recebido em I9 maio 2007 / aprovado em I5 jun. 2007.

\section{Para referenciar este texto}

PEREIRA, D. de F. F. Educação de jovens e adultos e educação popular: um olhar histórico sobre as políticas públicas ou ausência delas. EccoS, São Paulo, v. 9, n. I, p. 53-74, jan./jun. 2007. 